\title{
Study on Total Quality Management System Construction for Higher Education
}

\author{
Jun Li \\ Yibin University, Yibin, 644000, China
}

Keywords: Higher education; TQM; Construction; Study

\begin{abstract}
Total quality management (TQM) system of higher education is related to formulating college functions, and implementing quality policy, objective and responsibilities. Higher education information resources and service quality system is continuously improved through comprehensive utilization of various quality management methods. This paper designs specific contents and implementation strategies for higher education to apply this system and finally point out tge possible problems and solutions during implementation of TQM system.
\end{abstract}

\section{Connotation of TQM of higher education}

Quality management coexists with production, marketing, finance and accounting and aims to formulate and implement quality policy, objective and responsibilities. Quality management theories and methods refer to a series of research theories and methods for development and implementation of relevant quality management projects. The purpose is to better evaluate features of quality management theories and methods through review on quality management theory and method study, and indicate deficiencies in the study and specify the next research direction so as to provide certain guidance for theory development and reality. Japanese enterprises define TQM as the following values; (1) customer first; (2) employee first; (3) attach importance to teamwork; (4) attach importance to safety; (5) encourage sincerity; (6) require all to participant; (7) process first.

Quality management system of higher education includes four aspects: 1) quality management system is a constituent part of organization and management system and also a set of system established by an organization to ensure product and service quality; 2) quality management system and authentication have no equal relation. Authentication is just a means to gain approval of some quality management systems; 3) for the organizations valuing quality, no matter whether they are certified, perfect quality management system should be established; 4) perfect quality management system includes correct quality management philosophy, effective quality management method and resources used to form quality. Quality management system of higher education aims to meet users, comprehensively utilize various quality management methods and continuously improve higher education information resources and service quality system.

\section{Necessity of applying TQM system for higher education}

At present, an urgent task for higher education is TQM system and service quality system authentication, supply of high-quality products, adaptation of information society and service for students. The significance is as follows:

\section{Convenient for enhancing higher education competitiveness}

After China joined WTO, higher education will gradually blend in economic global system like other public interest and other fields. Higher education information service and development will be faced with new opportunities and challenges. The addition of foreign investors gives rise to serious impacts on China's information service subject (higher education). In the face of fierce market competitions and the quantity of information services, the information popularity and quality reputation of an enterprise become the first target when users select service providers. 


\section{Convenient for improving quality awareness of higher education workers}

Higher education workers may participate in training and practice through some organizations for all-round learning, then improve management consciousness and achieve higher-level participation in higher education management. In this process, quality awareness gradually becomes an important factor for higher education quality management standard to be really implemented in daily behaviors of higher education workers. Through discovering and solving problems, higher education workers can form quality management environment "living quality", or conscious actions are improved through employees' comprehensive quality to ensure basic management system for effective operation.

\section{Convenient for facilitating sustainable development of higher education}

TQM system construction for higher education is of great significance for sustainable development of higher education. It can not merely improve school-running quality of higher education, but also make higher education sustainable development. During establishment and implementation of higher education quality system, the usual practice is not adopted, but fixed standards pre-established by the appraisal agency to measure higher education.

\section{Basic contents of TQM system construction for higher education}

\section{Information service quality management}

Firstly, we should explicitly formulate service quality policy and objective. In the era of big data, as quality management system generates increasingly large influence on human life, discussion on college information service quality management system becomes the need of era development. During researches on quality management system, the functions of information and data as well as ordeal of quality management system on human life in recent years will certainly be cognized again. The defects of "anthropocentrism" can be effectively analyzed through education and case analysis. It is required to deeply cognize such wrong idea, guide students to master the methods to improve quality management system and promote harmonious coexistence of students and teachers in colleges. Quality management system study in college class can effectively facilitate harmonious coexistence among people. Economic-centered and economy-centered practice is to some extent transience and wrong. Popularization of quality management idea among college students contributes to their formation of life employment view and advanced thought so as to guarantee continuous and healthy development of China's economy and correct treatment of interpersonal relationship.

Secondly, we should specify design of quality system structure and system elements, students are the key to quality system. They often take part in service supply in this process and directly evaluate the process effect. The starting point is the need of student service, and the final result is service. It is required to pay special attention to specific information control process. It is necessary to formulate quality manual as needed provide work duties, rights and mutual relations, confirm higher education service quality system elements, formulate corresponding program file system for main emphases in service quality process, specify the division of labor, make everyone clearly realize their duties, and formulate post norms according to job nature, job requirements, service standards and quality control norms. Student service demands continuously change and develop. Since 1080s, student demand has developed to current professionalization, service and information technology. It is required to combine the features to conduct all-round and multi-level study and exchange for student service demand, know the structure, classification, title index and service setting of students, sort, summarize and analyze results and form student service abstract so as to lay a foundation for student service design.

\section{Service resource quality management}

Firstly, provide core service, i.e. provide consultations and information retrieval service (media file information) to meet user demand for knowledge and information. Such service can be called real service and the core of user need. Secondly, provide form service. It means attitude and efficiency are used to meet users' some mental and spiritual needs and wishes. Thirdly, add service means. Various kinds of convenience are provided for users' reading, rest, diet and accommodation. Perfect service 
and additional service form should closely focus on core service. In this process, information resource classification and catalogue will have direct influence on higher education management and service quality. Fourthly, perfect higher education quality system file. After higher education quality system file is finished, trial operation will be conducted to test quality system file and coordination efficiency, improve information disclosure and further perfect quality management system file.

It is required to fully specify whether quality management system is rational ad quality records play a role. The specific manifestation is as follows: 1) improve subscription channels. With the help of information technology, subscription channels of higher education increase greatly and develop to multiple approaches such as publishing house and supplier from printed books. Electronic tools should develop energetically. Information technology may be utilized for electronic transformation of college management. The latest book data may be gained through interviewing personnel. It is necessary to explain that information resource organization by higher education generally includes library collection layout, arrangement and book reservation. They have equal important functions in information resource utilization process.

\section{Human resource quality management}

First of all, specify system objective. Higher education workers are valuable wealth of higher education. During participation in value transformation activity, workers achieve their life value. The objective of human resource quality management system of higher education is to boost higher education service competitiveness and attraction under network environment and maintain competitive edge.

Secondly, specify specific steps. To realize these objectives, human resource quality management system of higher education is divided into three steps; in classroom, teachers should dare to propose the latest cases of quality management system for evaluation, encourage students come up with their ideas on cases, boost students' self-study ability with the help of media resources, improve their cognition of quality management system protection in the form of sharing and exchange and boost the value of network text in ideology cultivation. Firstly, positively accept and make good use of network text. It is required to adapt swift and violent development of multimedia technology as well as microblog and WeChat and text form of creative ideology communication; secondly, create network micro-environment for undergraduates. It is required to create ideology for undergraduates after 1990s generation through network text interaction, creativity and group, make undergraduates experience the situation and achieve dynamic aesthetic demand; thirdly, network communication approach of creative ideology. It is required to utilize documentary, special image, academic forum and college website to achieve transformation from orthodoxy of traditional texts to network text flexibility, weaken political color of website, regard the website as the main platform and focus on hot issues and difficult problems to guide students to approve relevant education.

Finally, it is required to clearly know system model of human resource quality management system of higher education. (1) Total quality management system module. Human resource quality management system accords with requirements of quality management system. Existing higher education management system is reconstructed through optimization of human resource. So, it occupies an outstanding position in the system. Understanding and mastery of this module is the first step of quality management system construction. (2) Management module. "Leadership role" is in the second position in 8 quality management principles. Dynamic control plays an important role in quality management system. In order to achieve customer satisfaction target and long-term stable development of higher education, strategy and strategic target among "standards" as well as the awareness and ability of achieving employment are also prominent. (3) Human resource strategic planning module. We call it inner management module of human resource. Independence of the module reflects the functions of human resource library and human resources strategic planning of quality control center. (4) Human resource inner management module of higher education. This module includes recruitment, employment, training, performance assessment, salary management and vocational development of higher education personnel. The function of the module lies in indicating how to form quality management system and optimization of human resource management to attract and retain talents. (5) Worker satisfaction module. This module regards employees as 
internal customers of an organization from the perspective of customer relation management. Here, we regard it as one of preconditions of student satisfaction. (6) Student satisfaction center module. It covers three sub-modules: service quality, customer satisfaction and sustainable development.

\section{Quality management of students' behaviors in colleges}

College students will finally face society, while society is different from campus life. The former emphasizes rules, responsibilities, cooperation and innovation. So, college education should carry out necessary consciousness of responsibility and professional behavior norm education for students. This has great benefits for students to rapidly adapt occupational needs and efficient fusion in society. The details are as follows: (1) intensify behavior norm education. In view of inherent shortage of school education in standard education, educational experts, human resource experts, entrepreneurs and excellent enterprise talents may be employed to set up special course training and lectures to enhance this educational function to make college graduates directly know social and economic development form, know of enterprise needs and employment standards, understand basic ability and quality, then influence their development view, make them enhance their comprehensive ability with certain purpose and plans, and shape professional spirit and practice professional behavior norms. (2) Cultivate positive, optimistic and confident attitude to life. In current social life state with fast pace and high pressure, positive, optimistic and confident attitude to life are essential skills for human survival and development. College students enter society from campus. Under serious employment pressure, they will inevitably encounter setbacks and failures. Without optimistic and confident attitude to life or up-and-coming life belief, they will not have the joys of success. Hence, colleges should enhance frustration education and pressure education, strengthen students' anti-pressure ability, guide them to develop self-regulation, self-amendment and self-adaptation social survival and development ability. (3) Improve students' professional spirit. Professional spirit content should be fused in moral education course. Original ideological and political education mode should be altered. Professional spirit education with more practice significance is fused in the course. It is necessary to boost students' learning interest through specific case teaching, help them establish correct professional idea and value, improve their confident and optimistic occupation selection spirit and enhance their innovation and business startup will and ability. Besides, double-professionally-titled teacher team construction should be valued. Teachers should also fully know development situation and talent demand status of industrial economy, and make talent cultivation more targeted and practical except solid professional knowledge. Meanwhile, colleges should provide more employment and practice platforms and increase opportunities for students to contact social practice and know enterprises’ work state.

\section{References}

[1] Zhan Tao, Thought on innovative talent cultivation in research-based universities. Journal of Higher Education, 2012 (01)

[2] Yi Juqing, Difficulties and solutions fort colleges to implement quality-oriented education. Heilongjiang Researches on Higher Education, 2011 (01)

[3] Yuan Guiren, TQM is ore task of higher education reform and development. Teaching and Education, 2010 (03) 